\title{
Looking into Theme-Rheme Structure through Demand Letters as Collection Instrument
}

\author{
Henreitta D. Miranda*
}

Bulacan State University, Philippines

\begin{abstract}
This research focused on demand letters, one of the most influential tools in business communication; on how they are written with the use of Systemic Functional Grammar of MAK Halliday. The purpose of this study is to understand and analyze these letters which are being manipulated in order to deliver the right context based on the needs of the writer. This paper studied three different types of Demand Letters, and identified the Theme and the Rheme of each of the sentences. Textual Analysis was employed in order to identify how the structure of demand letters delivers the subliminal messages embedded by the writers. Through Textual Analysis, the research is able unearth and foresee potential messages. It was found out that demand letters are often written using Unmarked-Marked Theme, which indicates that these letters are elaborately crafted in order to cater various meanings in just one sentence. The way in which writers develop their sentences can reveal their stance and intention. Additionally, it was discovered that most demand letters are written on a Derived Theme Progression which means that the initial sentence in the letter contains all the necessary information and succeeding sentences are just additional information. The letters appear to be written in a way in which all the primary details were compacted in the first sentence, primarily due to urgency and time constraint. This study will be very beneficial to the academe as this becomes a proof that schools should start honing people to become more sensitive about unuttered messages through incorporating Functional Grammar to lessons.
\end{abstract}

Keywords: Demand Letters, Theme, Rheme, Functional Grammar

\section{Introduction}

The Philippine economy as of writing is considered to be at its weakest according to Philippine Statistics Authority (PSA). With the growing number of economic issues that Filipinos face every day, it is hard for minimum wage earners to buy basic needs and much harder to acquire things that may satiate their perceived needs. The economic weakness is manifested through the inflation rate of $6.7 \%$ based on the report of PSA this September 2018. For some, this seems to be only a number, but economists consider this as a great factor that affects the buying capacity of people specially the working class. Due to this situation, the ideal thing to do according to frugal people, is to buy things which are of extreme importance and live within one's means. But this does not normally happen in the Philippine context. Based on the study conducted by Living Life Philippines (2017), four out of ten Filipinos pay debts for things which are not really necessary just like cars, houses, credit cards and appliances. The worst part is, Filipinos acquire these things through short term loans given by money lenders, small scale financial institutions and banks. According to the Credit Card Association of the Philippines (CCAP), the number of people who subscribe to credit cards has grown to 3 million in which most of them came from the working class.

Additionally, studies showed that the meager income of these individuals makes it hard for them to pay their loans. Hence, the cases of unpaid debts have grown exponentially. Lenders consequently, in order to get back what they have invested and the projected income, resort to coercing measures like calling, sending text messages and sending demand letters through courier to notifying a borrower about the unpaid amount that includes the principal and interest. These collection schemes are normally done by a third party, a collection agency, which rely heavily on the collected amount for their income. Therefore, collecting agents have to do their best so debtors may be obliged to pay their debts. Interestingly, the most common collection instrument that is used based on study conducted by Philippine E-legal Forum in collecting unpaid debts is the demand letters. 
Demand letters are primary communication and business tool. With the growing number of unpaid debts and demand letters sent, makes the latter a good ground for study. The aim of this research is to analyze demand letters' content and interpret subliminal meanings that can potentially impact a reader's disposition. This research will make use of textual analysis which is one of the metafunctions based on the Systemic Functional Grammar (SFG) conceptualized by MAK Halliday as cited by Matthiessen (2004).

According to Barthes (1977) in his study on Learn More in Game Literacy, textual analysis is a good way to unearth the embedded meaning of text, coded path as point of take-off and its intended impact. These salient features of textual analysis were also used by Oyoola (2013) in his study on propaganda advertisements of political parties in Nigeria. His research displayed the same effectiveness as shown in the study of Barthes by identifying the themes of the conflicting parties. The said authors are concrete proponents on the effectiveness of textual analysis. Theme and Rheme are important features of a sentence according to Matthiessen (2004), since on one hand, Themes serve as the point of take-off in sentences and on the other hand, Rhemes explain more about the Theme. As such, whatever information delivered through the Rheme is subjected to recall. Themes make the reader anticipate for information to be delivered through the Rheme.

Additionally, according to Potter (2016) on her study about Ideological Representations and Theme-Rheme Analysis in English and Arabic News Report, themes are not arbitrary in fact they can be manipulated and bended to suit the need of the writer. Hence, Theme- Rheme analysis is very suitable to this current study in order to illustrate how a writer of demand letters position himself and make the reader feel the need to read the succeeding information being delivered. This idea of Potter was seconded by the study of La Polla (2018) which posited that meaning doesn't exist externally instead it is subjectively being created in the mind and is manifested in actions. People create meaning from these manifestations and it is where assumptions are created.

The growing number of researches done that made use of textual analysis gives this process a high reliability and makes it a sturdy framework for this study. Although there had been a lot of researches conducted using textual analysis, the use of demand letters remains to be an unexplored area of concern. Hence, the current study would like to achieve the following goals: First, identify how demand letters are constructed using ThemeRheme. Second, what subliminal meaning can be derived from the Theme-Rheme Structure in demand letters. Finally, how may the usage of Theme Rheme in demand letters affect the interpersonal relationships of the writer and receiver.

Demand letters however seem to be of less importance in the Philippine context, as noted on the report of Limtingo (2010) in Philstar GLOBAL, due to lack of semantic awareness of people, still this attempt of understanding the nature of demand letters finds its way to be very useful in helping teachers and students understand texts in whatever field of expertise they may have. The current study of demand letters can be very useful in educating readers on how to be more sensitive with hidden meanings of text and structures. Business Communication and English for Specific Purposes are among of the beneficiary fields of learning that may benefit on this endeavor. Additionally, collection industry: lender and debtor, may also benefit as they become more sensitive with unuttered messages that they give and receive respectively.

\section{Method}

The current research used SFG specifically the Textual Analysis in recognizing how demand letters are structured, making use of Theme and Rheme. Demand letters requesting payment for a delinquent credit card, a housing loan, and an appliance loan were scrutinized and analyzed in order to identify the subliminal messages through the usage and arrangement of words and phrases that constitute the Theme and the Rheme. In this research, only the analysis on how the demand letter for credit cards was presented to show the process done. But a table was presented to reveal the analysis of other types of demand letters. For the purpose of ethical 
consideration, the names of: the client, the bank, contact person, and sender were withheld to preserve their identity.

In understanding the demand letters, this research had undertaken the following steps: identify the Theme and Rheme of each of the sentences. Next, analyze the effect of the arrangement of words and phrases in Theme and Rheme to the supposed meaning of the text. Finally, identify how the text can potentially affect interpersonal relationships.

With all of the above mentioned steps undertaken to interpret the data, the researcher made use of the Textual Analysis posited by MAK Halliday. Unlike any other type of framework, SFG includes contexts, codes and functions in interpreting text. Hence, this concept was found to be most appropriate.

Datum 1 Credit Card Demand Letter

February 26, 2018

Name of Client

Address of Client

\section{RE: Unpaid Credit Card Purchases \\ Bank Credit Card No. 12345678910113 \\ Outstanding Amount Php 88,386.67}

\section{Dear Client:}

Once again, we are writing you on behalf of our client, Name of the Bank (withheld), in line with your nonresponse to our recent letter requesting you to please settle your past due balance amounting to P8,837.00, inclusive of interest and penalties, as of February 20, 2018.

Because you have not communicated with us to inform us of a desired mode of settlement of your past due balance despite our earlier letter, we are therefore making a FINAL DEMAND and are requesting you to please settle/pay directly to our client the outstanding balance amounting of P88,386.67 or minimum amount P8,837.00 within FIVE (5) calendar days from the receipt of this letter.

We trust that, like us, you want to put this matter to rest. Thus, to avoid any further inconvenience for both you and our client, we urge you to take advantage of this opportunity to pay your unsettled balance.

Once again, should you desire to get in touch with us, feel free to call Contact Person (withheld) at tel nos. 09471234567, 09261234567,7092345, 7092346, 7092347,7092345 kindly indicate your full name and card number if you will send us a text message or you may email us at collector@bills.com (withheld).

Very truly yours,

\section{Sender Name (Withheld)}

Note: If payment has been made, kindly disregard this letter. Please call or email your proof of payment to our office in order for your account to be updated and returned back to our client NAME OF THE Bank. 


\begin{tabular}{||r||c|c||}
\hline Once again & we & $\begin{array}{l}\text { are writing you on behalf of our client, Name of the Bank (withheld), in } \\
\text { line with your non-response to our recent letter requesting you to please } \\
\text { settle your past due balance amounting to P8,837.00, inclusive of interest } \\
\text { and penalties, as of February 20, 2018. }\end{array}$ \\
\hline \hline Marked Theme & $\begin{array}{c}\text { Unmarked } \\
\text { Theme }\end{array}$ & \\
\hline \hline
\end{tabular}

Figure 1 First Paragraph

In the first paragraph which is just composed of one sentence, the immediate use of the phrase "Once again," by the writer which is an Unmarked Theme before the Marked Theme, "we," is a style that shows the following subliminal messages: first, it tries to establish authority. This is to show that the person behind the letter was given the right and authority to write this communication. The writer by using this phrase reiterates the problem that has been previously raised. "Once again" is used, according to a dictionary, when one wishes to indicate that the same action has been done previously or repeatedly. With the usage of this phrase alone at the beginning of the sentence can make the reader assume that the concern being presented is no longer pristine. That there may be series of communication sent, but the recipient still remains to be noncompliant.

The Marked Theme in the first paragraph was supported with the phrase "in line with your nonresponse to our recent letter." This technique that the writer used, allows the reader to anticipate the information that the Rheme contains. The process that the writer used in the introductory sentence was a Linear Theme- Rheme approach, in which the intention of the writer was to simply emphasize the details found in the Rheme. Thomas (1999) stated that in Linear Theme-Rheme, the Rheme of the previous sentence will be the Theme of the succeeding sentence, though they may be differently worded. The emphasis on the details found in the Rheme was augmented with the use of graphology. One may note how the writer intentionally used bold letters on these three most important details found in the Rheme; name of the bank, the owed amount and date. This Linear Theme- Rheme style was crafted not only to put stress on this information, but it also makes the writer ensure that reader will notice immediately the said details in case the receiver chooses not to read the entire letter. Following the definition of Thomas (1999) of Linear Theme-Rheme notice how the Rheme of the first sentence, becomes the Theme of the subsequent line.

This paragraph is just a one-sentence declarative format, in which the sole purpose is to introduce the reason or the problem. According to Matthiessen (2004) declarative sentences are the ones mostly used when one is introducing an idea with vague to no prior context. Hence, in this data, the writer purposely chose to use the declarative form in order to state facts and assumes that the reader may not have previous knowledge of the issue. Despite the usage of the phrase "once again," the writer gives the benefit of doubt that the reader may have not read the previous letters sent. 
Because you have not communicated with us to inform us of a desired mode of settlement of your past due balance despite our earlier letter, we

\begin{tabular}{|c|c|c|}
\hline $\begin{array}{l}\text { are therefore making a } \\
\text { FINAL DEMAND }\end{array}$ & and & $\begin{array}{l}\text { are requesting you to please settle/pay directly to our client the } \\
\text { outstanding balance amounting of } \mathbf{P 8 8 , 3 8 6 . 6 7} \text { or minimum amount } \\
\mathbf{P 8 , 8 3 7 . 0 0} \text { within FIVE (5) calendar days from the receipt of this letter. }\end{array}$ \\
\hline RHEME 1 & conjunction & RHEME 2 \\
\hline
\end{tabular}

Second Paragraph Figure 2

The second paragraph that was used in this letter is an example of a Thematic Equative, which was defined by Matthiessen (2004) as a type of sentence in which there is switch, the Rheme in normal sentences becomes the Theme in this type and be-verbs are used as separators. This definition is true to the sentence indicated above.

Additionally, Matthiessen posited that the best type of theme to use when a writer wishes to emphasize a longer idea is the Thematic Equative. This approach is very suitable for sentences which need impact. In the second paragraph of this demand letter, the writer intends to bring much emphasis on the message that this has to deliver by making the phrase "Because you have not communicated with us to inform us of a desired mode of settlement of your past due balance despite our earlier letter, we" as the Theme. The clinical definition of Theme according to Merriam Webster, it is the topic or subject of talk. Hence, for the writer, this phrase means so much therefore he has placed it in the trajectory part of the sentence. The Rheme part of this sentence is composed of two Rheme which were given equal treatment. The first Rheme which is focusing on the idea "final demand" used visual foregrounding to make it stand out by using all capital letters. The usage of "and" as conjunction indicate that the two clauses should be taken with equal function and weight.

Similar to the first Rheme, the second Rheme contains foregrounding with the use of bold letters on this information: amount and days. The information stressed on both Rheme is of equal importance as manifested in the use of the conjunction "and." Based on the known definition of the word "and," it is used when connecting grammatically coordinate words.

The second paragraph was also constructed using a declarative sentence, but this was constructed intended to be one-sided. The writer left the reader no choice but to accept the idea that the sender wishes to receive the mentioned amount on that particular day. 


\begin{tabular}{|c||c|c||}
\hline We & \multicolumn{1}{|c||}{ trust that, like us, you } & want to put this matter to rest. \\
\hline \hline Unmarked Theme & \multicolumn{1}{|c||}{ Marked Theme } \\
\hline \hline \multicolumn{2}{|c|}{ ThEME } \\
both you and our client, we
\end{tabular}

Figure 3 Third Paragraph

The third paragraph in this demand letter is the antithesis. It is composed of two simple sentences that use the linear type of theme. But note the use of the Unmarked Theme on the first sentences, which is attributed to selfvoice by Al Bakaa (2015). Self-voice is a style in writing normally used to present an opinion. In this sentence, the writer intentionally placed the Marked Theme in between the Unmarked Theme "We" and the Rheme "want to put this matter to rest" for two purposes. The first reason: the writer wants to assume that the reader also would like to share her opinion in ending the issue. This becomes a mind conditioning tactic. The second reason why the writer used this style is: he wants to make the statement less offense in nature. Unlike the other statements that were used in the letter, this sentence engages the reader and promotes the feeling of genuine guidance. Through this sentence, the reader can imagine a true friend telling him that the best thing to do with this problem is to settle it.

The second sentence of this paragraph is a statement that pushes the reader in settling the debt. The written phrases used mind conditioning which subtly tells the reader about the urgency in paying the delinquency since this may be the one last opportunity that will be given before a drastic step will be undertaken. Note the use of the phrase "to avoid any further inconvenience for both you and our client" which serves as a sign which indicates that further steps may be done in order for the lender to get what is legally his.

The type of sentences that were used in this paragraph is declarative in form but they function as imperative sentences. Imperative sentences are sentences that give orders. This type of sentence is used when a person emphasizes his authority over the other consequently compelling the listener or to comply. This concept of imperative sentence as a tool used to show authority in either spoken or written language is supported by the study of Lin (2019) on her study about discourse function of Marked and Unmarked on the narrative nature of Chinese as language learners of English. On her study, it was found out that the type of sentence used and position of the theme and rheme indicate a standpoint. The previously mentioned study is a concrete example on the importance of the structure and arrangement of themes in written text which is evident in the third paragraph. 


\begin{tabular}{|c||l|l|}
\hline Once again should you desire to \\
get in touch with us & $\begin{array}{l}\text { feel free to call Contact Person at tel nos. 09471234567, 09261234567, } \\
\mathbf{7 0 9 2 3 4 5 , 7 0 9 2 3 4 6 , 7 0 9 2 3 4 7 , 7 0 9 2 3 4 5} \text { kindly indicate your full name and card } \\
\text { number if you will send us a text message or you may email us at } \\
\text { collector@bills.com. }\end{array}$ \\
\hline \hline THEME & RHEME \\
\hline \hline
\end{tabular}

Figure 4. Fourth Paragraph

The last paragraph of this demand letter is just a simple Theme and Rheme pattern. The Theme indicates that the writer is telling the reader a suggestion with the use of the modal verb "should." The technical meaning of "should" based on the definition of British Council, it is a modal that tries to give opinion, suggestion, preference or idea. In this sentence, the writer is simply suggesting for the reader to do the first step in resolving the issue; contacting them. Notice how the writer provided numerous ways on how to communicate with them. It provided the cellphone numbers, telephone numbers and email. What the writer implies by providing these information is, they are very much willing to get in touch and their line of communication is widely open for the reader. Although this last sentence appears to be the trough of the communication still it emphasizes the importance of contacting the writer in order to settle the account. Let us take note on how graphology again was used in the contact information. This style suggests that, though the letter has ended, still the ordeal of the reader has not. The only solution is contacting the writer.

\section{Discussion}

Table 1 Summary of Theme-Rheme Types Used

\begin{tabular}{lccc}
\hline Type Demand Letter & Simple Theme-Rheme & Thematic Equative & Marked- Unmarked \\
\hline Credit Card Loan & 2 & 1 & 2 \\
\hline Housing Loan & 1 & 2 & 4 \\
\hline Appliance Loan & 4 & 6 & 7 \\
\hline Total & 7 & 9 & 13 \\
\hline Percentage & $24 \%$ & $31 \%$ & $44.8 \%$ \\
\hline
\end{tabular}

The data above show that most of the demand letters which were analyzed in this study used the third type: Marked and Unmarked Theme and Rheme. Matthiessen (2004) discussed that, the choice of Theme in sentences make a primary role how the discourse is organized and he calls it Method of Development. From the data taken from different kinds of Demand Letters, the result above indicate that most demand letters make use of Unmarked-Marked Theme Approach. According to the definition stated about Marked Themes by Matthiessen, they are mainly used when a writer wishes to elaborate what is the topic about. This style in writing provides a clearer picture about the subject of the sentence. Additionally, this approach can also define the status of the sender and the receiver of the demand letter. The Theme-Rheme concept is believed to enhance the awareness of a person's coherence either in spoken or written language. The idea of coherence is supported by the study conducted by Laya (2015). On his study about Theme Theory, he concluded that the choice of theme can contribute to the meaning of a message. Laya therefore suggests that it is important for a writer to develop theme awareness in different moods in order to fully send the message across to the readers.

In most of the letters analyzed, the writer used the Unmarked-Marked Theme Approach in order to establish the relationship of the sender and the receiver. See Figure 1, which used the phrase, "Once again." This Marked Theme is just an elaboration and may not be essential in providing the message. This can be removed without affecting the details. However, along with this phrase are subliminal meanings. The first inference is, series of contacts had already been made by the sender but the recipient never heeded, resulting to use of the phrase showing the authoritative stance of the writer. This style is attributed to abductive inference as stated in the study of Wang (2006) about creating meaning. One can also infer that the writer is already getting fed up with 
the nonchalance of the receiver. Another inference that can be drawn is, further noncompliance can result to drastic actions such as court cases, visitations and persistent phone calls.

Another emerging concept evident in the different demand letters used in this study, is the Derived Theme Progression technique in writing. This idea was coined by Danes as cited by Carter-Thomas (2017) in her study Thematic Networks and Text Types. Derived Theme Progression technique is a type of writing text which has a central theme and subsequent themes are supporting themes. Succeeding themes are all derived or hinged from the central theme which is always found at the beginning of any composition. Derived Theme Progression is a writing style that makes use of topic sentence as a Central Theme. This primary trait that distinguishes Derived Theme Progression from other type of organization in writing is evident in all of the sample demand letters used in this study. Refer to Figure 1 as the central theme in the sample presented. This sentence is the initial sentence which conforms to the definition given by Dane about Derived Theme Progression technique. This sentence contains all the details and can be considered as the main topic. Notice how succeeding sentences refer to this paragraph.

Figure 2 focuses on elaboration of the reason why the demand letter is being re-sent. This sentence is anchored from figure 1 specifically on the phrases: "Once again," the name of the bank, the amount due and the expected due date. Note that figure 2 is just an elaboration and the topic is similar to figure 1 . The use of new words to reintroduce the same details is evident. Re-wording or rephrasing is another characteristic of Dane's technique.

Figure 3 is also connected to the figure 1. Note that figure 3 articulates the subliminal meaning embedded in figure 1 particularly the possibility pursuing drastic measures in order to collect the owed amount.

The last is figure 4 which is also a manifestation of the persistence of the writer which was reflected on the first paragraph particularly on the embedded meaning of the phrase, "Once again." In figure 4, the writer enumerated the different ways on how they can be contacted. Several options are provided to ensure that indifference is the only reason why the reader is unable to contact them.

The sample demand letter presented in Datum 1mirrors all other demand letters used in this study. The letter for car loan and small-scale loans for appliances share the same characteristics of the demand letter for credit cards.

Table 1 shows that the demand letters used in this study made use of Marked and Unmarked Theme and Rheme structure for sentence construction. Additionally, Derived Theme Progression technique for body development was also used. The combination of these styles makes any type of demand letter strong and indispensable. The strategies mentioned were also discovered by Chang (2018) in his analysis of Expository Essays. The strategies used in these demands letters were the same strategies used in the essays studied by Chang. It was concluded that organization and writing style play a major role in predicting meaning. Further, the author also mentioned that the strategies used in writing determine the quality, stance and coherence of a writer. One can identify an expert writer by simply identifying what type of theme-rheme used in a sentence.

\section{Conclusion}

From the study that was done on demand letters, it is therefore concluded that most writers of these business communication tool make use of the Marked- Unmarked Theme Type which is $44.8 \%$. This type of sentence is mostly used by writers in order to fully discuss and unravel their intention which they mostly embed in the words and structure they use in each sentence.

Data reflect that the letters used in this study were using the Marked- Unmarked Theme. This structure is designed to elaborate and emphasize important information by purposely placing them at the initial part of the sentence for emphasis. This structure intends to elicit recall and subsequently convince the reader in paying the debts through the use of strong words. 
Demand letters are conceived with the anticipation that readers do not finish reading the entire letter. Hence, Derived Theme Progression emerged as the composition technique used in all of the demand letters analysed in this study. This technique allows the writer to place the details onset of the communication which reduces the possibility of readers missing important information. This becomes a subtle way of compelling them to meekly submit to the demands of the writer.

In Derived Theme Progression, subsequent sentences in demand letters are merely clarifications and elaboration that are all hinged to the initial sentence which is considered to the main topic. With this style in writing, the writer is able communicate relevant details to the reader at one glance.

Further, the data illustrate that demands letters are strongly worded, heavily foregrounded, and cohesive. Writers intend to immediately create a huge impact on readers which can be traced to the nature of interpersonal relationships in the business industry. From the data used, all of the demand letters share the same characteristic, fast and short. These traits are time bound. The data show that in the collection industry, every minute counts, so everyone wants to go directly to the point. Clarificatory sentences though are included in the letters but they only add length to the body of the letter which can be factor of interest deterioration.

Writing demand letters appears to be superficial in nature and it does not support interpersonal relationship as manifested in the lack of rapport. With its absence, interpersonal relationship between the writer and the reader can never be established. Demand Letters though maybe strongly worded and heavily grounded cannot establish an effect to interpersonal relationships. Financial status and commitment still would dictate whether one adheres or disregards the demand..

\section{References}

Al Bakaa, Ali Jabbar (2015) Functional Analysis of Marked and Unmarked Theme in Demonstrating a Critical

Argument Written by Iraqi and Australian Post graduate Students: Theory and Practice Language Studies, Vol. 5. No. 2, pp 247-254

Barthes, Roland (2011). Understanding Texts. University of Waterloo

Carter-Thomas, S (1999). Thematic Networks and Text Types. Asp, 23-24.

Chang, Peichin (2018). Maintaining coherence in research argument: identifying qualitative differences between experts' and students' texts. Text \& Talk, Volume 38, Issue 6. Pages 655-682

Credit Card Association in the Philippines (CCAP) June 22, 2016, Retrieved from: http://www.ccap.net.ph

E-Legal Forums Vol. June 12, 2017 Retrieved from: www.natlawreview.com/article/so-your-business-received Demand-letter-now-what.

Halliday, M. (1994). An Introduction to Functional Grammar (2nd ed.). New York, NY: Oxford University Press Inc.

Lapolla, Randy (2018). Systemic Functional Language Description: Making Meaning Matter. London: Routledge

Limtingco, Ed F., (2010) How many collection Letters should you send? Philstar, October 27, 2010. Cebu, City, Philippines

Lin, Jiehua (2019) Discourse Functions of Marked Theme and the Narrative Nature of Chinese EFL Learners'

Argumentative Writing. Proceedings of RSU Research Conference, Rangsit University, Thailand.

Living Life Philippines. Issues October 12, 2017

Matthiessen, Christian (2004) Introduction to Functional Grammar of MAK Halliday, Hodder Headline Group

338 Euston Road London

Oyoola, Moses O., (2013) An Interpersonal Metafunction Analysis of Some Selected Political Advertisement in Some Nigerian Newspapers. International Journal of Humanities and Social Sciences, Vol. 3 No. 8 
Special Issue April 2013

Potter, Lorena (2016) Ideological Representations and Theme-Rheme Analysis in English Arabic News Reports: A Systemic Functional Approach. Functional Linguistics, 2016 Volume 3, Number 1, Page 1

Philippine Statistics Authority Issues 2018 Retrieved from: psa.gov.ph/business/price-indices

Wang, X. (2006). Grammatical concepts and their application in foreign language teaching. AARE Annual Conference, Adelaide. 